\title{
Bilim Tarihi, Kültürel Zaman ve Fuat Sezgin*
}

\section{History of Science, Cultural Time and Fuat Sezgin}

\author{
Prof. Dr. Şafak URAL (iD) 1
}

$\ddot{\mathbf{O z}}$

Fuat Sezgin'in İslam Dünyasında yapılmış olan bilim ve teknoloji konusundaki kapsamlı çalışmaları, sadece sıradan bir bilim tarihi açısından değil, kültür tarihi açısından da son derece önemlidir. Sıradan bilim ve teknoloji tarihi bize, bu alanlarda yapılmış ve zamanla unutulmuş başarıların neler olduğunu söylemektedir; fakat bir de bu başarıların bugünün kültürüne yansıyan özelliklerinden söz etmek gerekir. "Kültürel zaman" kavramını bildiğimiz "kronolojik zaman", "fiziksel zaman" veya "biyolojik zaman" gibi kavramlardan ayrı düşünmek gerekir. "Kültürel zaman" kavramının diğer zaman çeşitlerinden ayrılan tarafı, 'şimdi'nin, 'geçmiş'e varlık kazandırmasıdır. Diğer bir ifadeyle 'şimdi', kültürel olarak, kendi başına ve bağımsız bir varlık kazanma özelliğine sahip değildir. Bilim ve felsefe tarihi, sanat tarihi gibi alanlar, kültür tarihi açısından ama özellikle "kültürel şimdi" açısından son derece önemlidir.

Anahtar Kelimeler: Fuat Sezgin, bilim tarihi, zaman çeşitleri ve kültürel zaman

Makale Türü: Derleme

\begin{abstract}
Fuat Sezgin's intensive work on the history of science and technology in the Islamic world is really very important not only from the standpoint of ordinary history but of cultural time. Ordinary history of technology and science reveal some contributions which remain forgotten, whereas, on the contrary, we have to talk about the cultural side of history. We must think of "cultural history" as separate from the chronological time, physical time, biological or psychological time. Cultural history can give existence to "past" depending on the now. "Now", in the cultural sense, cannot exist independently of the past. The history of philosophy and science, as well as the art history, are more important for the cultural time and "cultural now".
\end{abstract}

Keywords: Fuat Sezgin, history of science, different kinds of time and cultural time

Paper Type: Review

\footnotetext{
* Bu yazı, 19.03.2019 tarihinde Uludağ Üniv. bünyesinde, F. Sezgin anısına düzenlenmiş olan toplantıya sunulan bildiri esas alınarak hazırlanmıştır.

${ }^{1}$ İstinye Üniversitesi, Fen-Edebiyat Fakültesi, safakural@safakural.com.
}

Atıf için (to cite): Ural, Ş. (2019). Bilim Tarihi, Kültürel Zaman ve Fuat Sezgin. Afyon Kocatepe Üniversitesi Sosyal Bilimler Dergisi, 21(Prof. Dr. Fuat Sezgin Özel Sayısı), 133-139. 


\section{Giriş}

"Bilim tarihi" denildiğinde geçmişte yapılmış olan çalışmaların tespiti ve bugüne aktarılması, yani unutulmuş olanların ortaya konulması akla gelir. Böyle bir işlem ilk bakışta sıradan ve basit bir eylem olarak düşünülebilir. Hatta böyle bir eylemin, unutulmuş, hiçbir işe yaramayan ve bugüne de bir katkısı olmayacak çalışmaların neler olduğunu ortaya koymanın sıradan bir merak içeren gereksiz bir uğraşı olduğu da düşünülebilir.

Gerçekten de geçmişte olmuş ve unutulup gitmiş hadiselerin günümüze ne gibi bir faydasının olabileceğini sorgulamadan önce, bilim tarihi çalışmalarına dünya çapında katkısı olmuş, dünyaca ünlü merhum Prof. Dr. Fuat Sezgin ve Ord. Prof. Dr. Aydın Sayılı'yı bu vesileyle minnet, şükran ve rahmetle anıyorum.

Bilim tarihinin öncelikle bir meraka dayanması, aslında onun ne kadar değerli bir uğraş olduğunun basit bir göstergesidir. Çünkü günlük yaşantımızda pek çok şeyi merak ederiz: kimin kiminle evleneceğini, evlenirken ne giyeceğini, tanıdıkların son tatilde nereye gittiğini, kısa bir süre sonra adı bile hatırlanmayacak dizilerin bir sonraki bölümlerini merak eder, derinden ilgi duyarız; fakat ancak gelişmiş kültürler entelektüel meraklara sahip olabilir. Gelişmiş kültürel beceriler, derinliği olan kültürel birikimler sonucunda elde edildiğini özellikle vurgulamak yerinde olacaktır. Elbette bu tür merakların toplumun tüm bireylerinin gündemini meşgul etmesi beklenemez; ama bir toplum, bu gibi kültürel derinliği olan konulara (da) ilgi gösterdiği, önem verdiği ve desteklediği ölçüde kendi kişiliğini bulabilir² .

Bir ülkenin refahının, gelişmişliğinin ölçütleri arasında ilk akla gelen hususlar elbette sahip olunan mühendislik eserleri ve teknolojik olanaklar, sağlık, eğitim gibi alanlardaki başarılardır. Fakat bu gibi alanlardaki başarılara da şüphesiz ancak kültürel bir birikimin sonucunda ulaşlabilir; zira bir toplumun değerler sistemini üreten, besleyen ve gelişimine olanak veren ortam ancak kültürel bir birikim sonucunda oluşturulabilir. İşte bilim tarihi, bu kültürün eseridir, ama kültürün de temel kurucu unsurudur.

Bilim tarihi, geçmişte olup bitmiş olayların keşfedilip gün 1şı̆̆ına çıkarılmasından, toplumun geçmişteki başarılarının ortaya konulmasından ibaret değildir. Gerçi geçmişteki başarılar, çok iyi bilindiği gibi, bir toplumun moral değerlerini biçimleyen, onları ayağa kaldıran, yeni çalışmalara zemin hazırlama özelliğine sahiptir. Ama köklü bir tarihin, toplumu rehavete sürükleyen, hatta tembelleştiren bir yanının olduğunu da görmemezlikten gelemeyiz. Kişilerin veya toplumların geçmiş başarılarıyla övünmeleri, günün sorunlarını görmemezlikten gelmek, onları çözmek çabasına girişmeden işin kolayına kaçıp üstlerini örtmek, övünerek bir rahatlama elde etmek gibi amaçlara da hizmet edebilir. Belki de işin en kötü tarafı, içinde yaşanılan dönemin sorunları için geçmişten hazır reçeteler aramaktır. İçinde bulunduğumuz zengin kültür coğrafyasının bugünü geçmişinden çok farklı renklere sahip olduğu ortadadır. Fakat zengin tarihi geçmişin bizatihi kendisinin, bugünün sorunlarını çözmede, başarılı olmadığı ortadadır. Geçmiş başarıların bugüne taşınması, onların günışığına çıkarılması tek başına yeterli değildir. Övünmek, sahip çıkmanın, ders almanın ve ileriye hamle yapabilmenin koşulu değildir. Böyle olsaydı, en basitinden özellikle mimari alanda tarihi hazineler barındıran İstanbul, Bursa, Edirne, Van, Erzurum, Ankara gibi şehirlerimiz tanınmayacak halde olmazlardı. Tarihin topluma değer katan yönünün birisi olumlu diğeri olumsuz iki yönlülüğü görmemezlikten gelinemez: ne bugüne bakarak geçmiş yargılanabilir ne de geçmişte kalarak bugünün sorunları çözülebilir. Bu karşıtlığı doğru analiz etmek ve çözüm yolları üzerinde düşünebilmek için "kültürel zaman" kavramını kullanacağım.

"Zaman” eksiksiz tanımını verebildiğimiz bir kavram değildir. Fizikçi ölçerek bu kavrama kendine göre bir varlık kazandırır. Newton sistemi, algılayandan bağımsız mutlak bir

${ }^{2}$ Bu noktada Aydın Sayılı'nın bilim tarihine yönelme sebebinin araştırmasını okuyucuya önemle tavsiye ederim. Bu konuda mesela Bkz: Demir R., Gökdoğan M. D. (2008) 
zamanın varlığından sözeder. Rölativist fizik ise, zamanın göreli olduğunu, çünkü gözlemcilerin bir fizik nesnenin hareketini kendi referans sistemlerine göre anlamak durumunda olduklarını söyler. Kuvantum fiziği, atom altı parçacıkların hareketini bir an içinde ölçmenin olanaksız olduğunu bildirmektedir. Günlük yaşantımızda kullandığımız "an" ve "şimdi” kavramları, algılayana bağlıdır; yani özneldir, çünkü algılayanın bilinci aracılığıyla varlık kazanır. Fakat buna rağmen bir gökcisminin belirli bir 'an'da nerede olduğu bilgisini nesnel olarak tespit etmek mümkündür. Çünkü hareket nesnel bir süreç olarak düşünülmektedir ve an'a da bu süreç içinde bir varlık kazandırılmaktadır. Halbuki atom altı dünyadan söz edildiğinde, öyle görünüyor ki, benim bilincime bağlı olan "an" ile fizik dünyada karşılığı olduğu düşünülen "an" birbirine karışmaktadır. "An" temelde benim bilincime bağlı olarak varlık kazanmaktadır; en azından bu sebeple, onu "salt bir fizik olgu olarak" kabul etmek hiç de kolay değildir.

Elbette sadece "an" kavramını değil, "zaman" kavramı da ne kuantum fiziğiyle ne rölativist fizik ne de Newtoncu fizik ile sınırlandırılabilir. Bu kavramı biyolojik açıdan/canlılar dünyasını dikkate alarak da ele almak mümkündür; böyle bir durumda ise, bir döngüsellikten söz etmek gerekir. Nitekim vücudumuzdaki süreçler, doğadaki değişim hep periyodik bir süreç içinde gerçekleşir; karnımız düzenli olarak acıkır, gece ve gündüz, mevsimler, hatta ölüm ve yaşam hep bir döngüsellik içerecek şekilde ortaya çıkarlar. Canlılar açıdan zamanı karakterize eden özellik, sonsuz bir ileriye gidiş değil, sürekli başa dönenen dairesel/periyodik bir süreçtir.

Psikolojik açıdan bakıldığında zaman, tamamen bilincime bağlı olarak varlık kazanan bir yapıya sahiptir. Korku ve acı dolu anlar, saniyelere sığdırılan yılları içinde barındırır. Sıkıntılı anlar geçmek bilmez, günlerce süren keyifli anlar ise bir gün gibi geçerler. Bilinç, olgulara varlık kazandırır; yani psikolojik açıdan zaman, kişinin (bilincinin) varlık kazandırdığı anların toplamıdır. Geçmiş, hatırlamalardan, şimdi farkında olma olgusundan, gelecek ise tahmin ve beklentilerimizden oluşmaktadır.

Bunlar dışında bir de "kültürel zaman" dan söz etmenin gerekli olacağını sanıyorum. Kültürel zaman, kültür olgusunun bireysel ve toplumsal yönlerini ortaya koymaya; daha da önemlisi, tarihi olaylarla kültür arasındaki ilişkiyi temellendirmeye olanak vereceğini düşünüyorum.

Kültür olgusu, hem bireysel davranışlarının toplamıdır ama aynı zamanda bireylerin kültürel- davranışlarına yön vermek özelliği de taşımaktadır. Bireyler, içinde yer aldıkları kültürel iklimin doğrultusunda eylemde bulunmak durumundadırlar. Fakat diştan bakıldığında eylemlerimiz, bireysel tercihlerin bir sonucu olarak görülebilir. Trafik kurallarına uymak ya da uymamak bireysel bir tercih olarak düşünülebilir. Ama böyle bir davranış, o toplumun kültürünün bir sonucu olarak da yorumlanabilir.

Nasıl yorumlanırsa yorumlansın, kültürel kazanımların, kendiliğinden elde edilebilecek bir beceri olmadığını özellikle vurgulamak gerekir. Dolayısıyla trafik kurallarının tek başlarına değerli olmadığını düşünmek durumundayız. İlginçtir, tarih de kendiliğinden ve tek başına kültürel bir değer biçimleyememekte ve oluşturamamaktadır. Nitekim yukarıda da işaret edildiği gibi İstanbul başta olmak üzere tarihi şehirlerimizde bulunan eserler, o şehirlerin gerek mimari özelliklerini gerek şehircilik anlayışlarını tek başlarına biçimleyememekte ve o toplumun kültürünün yapıcı unsuru olmak özelliği taşıyamamaktadırlar. Bilim tarihi de buna benzer bir özelliğe sahiptir: bilim tarihindeki başarılar, tek başlarına, geleceğe olumlu katkı yapmadıkları gibi, zihinsel bir tembellik sebebi de olabilmektedir.

İşte "kültürel zaman" kavramı bu ve benzeri olguları anlaşılır kılmaya ve geçmişe bakışı yeniden düşünmeye, böylece geleceği de farklı bir açıdan görmeye olanak verebilir. Tarihin yeni bir gözle okunması, kültürel eğilimlerin ve becerilerin oluşturulmasında yol gösterici olabilir. Bireyler, tercihlerini benimsemiş oldukları değerlere göre yapmakta, bu değerler bireylerin davranışlarına yön vermektedir. Toplumsal kültür ile bireysel kültür arasındaki köprü, bireylerin tercihleri aracılığıyla kurulmaktadır. Bireylerin tercihleri kültürel dokuyu biçimlenmekte, kültürel atmosfer, bireylerin tercihlerini yönlendirmektedir. Bir tür kısır döngü olarak karşımıza çıkan bu 
olgunun aşılması ve kültürel dokunun değişmesi için "bireylerin eğitimini sağlamak gerekir" şeklindeki dilekler kendiliğinden bir sonuca ulaşamamaktadır. Bu gibi dileklerin oyalayıcı olmaktan çıkarılması ve bir aldatmaca olarak kalmaması için, felsefeye ve sosyal bilimlere önem ve değer verilmesi, bu alanlarda çalışma yapanlara olanak tanınması kaçınılmazdır.

"Kültür" kavram olarak artmayı, çoğalmayı ifade etmektedir. Bunun karşıtı, steril olmaktır; yani hiçbir şeyin üremediği, üretilemediği bir ortamın olmasıdır. Diğer bir ifadeyle bir toplumun kültürü, kendi içine kapatılır, tarih de özlemlerin konusu halini alırsa, değişen ihtiyaçlara cevap verecek 'kültür'ün oluşması imkânsız hale gelecektir. İşte bu noktada 'kültürel zaman" kavramından söz etmek yerinde olacaktır.

Zaman, gerek bilimde gerek günlük kullanımında, ileriye doğru sürekli bir akışı ve bizden bağımsız bir geleceği ifade etmektedir. Halbuki "kültürel zaman", geleceği öngörme, onu inşa edebilme imkanını içinde taşımaktadır. Kültürel zaman açısından gelecek ve geçmiş, şimdi'nin içindedir. Kültürel zaman açısından bakıldığında geleceğin aslında, (örneğin fiziksel zamandan farklı olarak) bizim tarafımızdan belirlendiğini söylemek gerekir.

Günlük yaşamda geçmiş, olup bitmiş hadiselerin biçimlediği ve artık geri döndürülemez anılardan oluşacak şekilde düşünülür. Geleceğe, kader kavramı aracıllğıyla bakarsak, değiştirilemez bir özellikte olacak şekilde yorumlamak gerekir. Ne var ki zamanın bizzat kendisi, geleceği belirlemek özelliği taşıyan bir varlık yapısına sahip değildir. Kaldı ki, yukarıda da işaret edildiği gibi, farklı zaman kurgularından söz etmek gerekir. "Kültürel zaman" kavramının özelliği, geçmiş ve geleceğin, "şimdi” kavramı aracılığıyla düşünülmesine olanak vermesidir.

Newton fiziğinde bir nesnenin hareketi, zamana bağlı olarak hesaplanır. Bu hesaplama herhangi bir nesnenin şimdisi hakkında bilgi içermediği gibi, bir nesneye özgü "şimdi"den söz edilmesine de olanak vermez. Böyle bir dili veya kullanılan yöntemleri kültür olgusuna uygulamak da dolayısıyla mümkün değildir. Halbuki kültürel ve toplumsal olaylarda "şimdi" belirleyici ve yön verici bir özelliğe sahiptir. En önemlisi de "şimdi" bize geleceği rasyonel olarak kurma ve öngörme olanağı sağlar. Fizik olaylarda geleceği öngörmek elbette mümkündür: bir gezegenin hareketini sadece öngörebiliriz ama onu kurgulayamayı.

Kültürel olgulara -aidiyet duygusu ${ }^{3}$ bireysel beceriler, ortak katılımlar, sosyal ve teknolojik olanaklar, toplumun çağın gereksinimlerini karşılama esnekliği, liyakate verilen öncelik, teknolojik yetkinlik, şehirlerin yapıs1- yön verebilir; bu yön vermeyi ise "şimdi" aracılığıyla kurgulamak mümkündür. Kültürel zaman, şimdi üzerine kurulmuştur: şimdi, geleceği kurgulama, biçimleme ve inşa etmek olanağı sağlar.

Zamanın kültürel yönünü üzerine inşa edebileceğimiz "şimdi", psikolojik şimdiden farklıdır. Bir toplumun tarihinde yıllar, hatta asırlar 'şimdi'yi, yani 'an'ı biçimleyebilir. "Osmanlı döneminde geçerli olan bazı değerler şimdi de varlığını sürdürmektedir" veya "cumhuriyet döneminde kabul edilmiş yasalar halen yürürlüktedir" denildiğinde yılları kapsayan bir zaman diliminin halen, şu anda da mevcut olduğu ifade edilmiş olur. Burada bizi ilgilendiren husus, geçmişin şimdi mevcut olması, ona şimdiye bağlı bir varlık kazandırmıştır; "şimdi”, geçmişi şimdiye taşımakla "geçmişin şimdi" sine varlık kazandırmıştır. Geçmiş, tarihi bir olgu olmaktan çıkmış, şimdi yeniden ve farklı bir varlık kazanmıştır. Diğer bir ifadeyle, kültürel şimdi, geleceği biçimleyebilme yeteneğini içinde barındırdığı gibi geçmişe de yeniden varlık kazandırabilir. Aksi taktirde geçmiş; tarihi olgular, anılar veya masallar olarak anılmak durumda olur.

Bilimin tarihi, bilimdeki gelişmeleri anlatan, ama artık yürürlükte olmayan olayların toplamıdır. Fakat kültür zaman açısından "şimdi" ona bir varlık kazandırabilirsek geçmiş, şimdiyi etkileyebilir ve biçimleyebilir. Bunun şartı, yukarıda da işaret edildiği gibi, o toplumun bir kültürel beceriye sahip olmasıdır. Bilim tarihi, geçmişte yapılmış olan bilimsel keşiflerin

${ }^{3}$ Bkz. www.safakural.com adresindeki ilgili yazılar 
bilinmesi ile sınırlı değildir. Bu noktayı, çok ilginç bir şekilde merhum hocamız F. Sezgin'in yazılarında açık olarak görmek mümkündür4:

Fuat Sezgin, bir medeniyetin doğuşu ve gelişmesi için 1) Geçmiş medeniyetlerin mirasının kararlı ve yoğun şekilde elde edilmesi ve öğrenilmesi; 2) Bu sürecin devlet tarafından sistemli şekilde desteklenmesi ve 3) Din tarafından rahatsız edilmemiş olması gibi üç temel unsurun sistemli bir biçimde birlikteliğine gerek olduğunu belirtmektedir. Ona göre bu yoldan alımlama gerçekleştikten sonra başarı elde edebilmek için de, alınan bilginin, deneyimin ve araçların sadece kullanılması değil, aynı zamanda yeni kültür çevresinin bir parçası olacak şekilde geliştirilmesi ve katkı yapmayı amaçlayan bir doğrultuda adeta yeniden üretilmesi zorunludur. Sezgin, F. (2008).

Dikkat edilirse açık bir şekilde, bilimsel faaliyetlerin ortaya çıkabilmesinin özel koşulları olduğu, bu faaliyetlerde tarihin özel bir yeri olduğu ifade edilmektedir. Kısaca, bilim tarihini okumak, okuyabilmek, önemini kavramak ve ondan yararlanmak kültürel bir beceri gerektirmektedir.

Aslında “oku!" emrinin bir süreklilik içermesi gerekir. Bu süreklilik yeniden okumayı ve anlamay1 gerektirmelidir. Bir roman söz konusu olduğunda insan onu genellikle bir defa okur; hatta bir fizik kitabını da okuyup anlamak yeterlidir; ama okunması gereken doğanın veya tarihin kendisi de olabilir. Elbette bu noktada, okumanın yanı sira anlamak ve akıl etmek de ayrica dikkate alınmalıdır. "Akıl etmek" hem okumada sürekliliği hem de okuduğunu anlayabilecek bir donanıma sahip olmayı gerektirmektedir. Doğayı 'okumadan' akıl edemeyiz, onu idrak edemeyiz, önemini ve büyüklüğünü kavrayamayız; doğanın dili (Pitagoras'ın, Galileo'nun, Heisenberg'in ve diğer düşünürlerin farklı şekillerde ifade ettiği gibi) matematiktir, geometridir. Okuyabilmek ve okuduğunu anlayabilmek için bu dili bilmek gerekir. Benzeri durum bilim tarihi için de geçerlidir ve bilim tarihini ayrıcalıklı kılan, bir toplumun kültürünün kurucu unsuru olmasıdır. Bu özellik, yukarıda da işaret edildiği gibi, moral değerlerden kültürel şimdinin inşaasına kadar uzanmasından kaynaklanmaktadır. Geçmişin bugünü inşa etmede kullanılabilmesi, bugünün (şimdisinin) geçmişi inşa etmek amacıyla kullanılabilmesine bağlıdır. Bunun ön koşulu, o toplumun kültürel bir beceriye sahip olmasıdır.

İbn Haldun'un dediği gibi coğrafya, toplumların kaderini belirler; evet ama coğrafya da değişmektedir. Çöller verimli tarım arazileri halini almakta, teknik imkanlar ormanların ve göllerin oluşmasına veya tam tersi yağmur ormanı gibi yerlerin tarım arazisi haline gelmesine sebep olmakta, Hollanda gibi ülkeler endüstriyel tarım sayesinde yepyeni bir coğrafi özellik kazanmaktadır. Yani kısaca bilim ve teknoloji, coğrafya ve kültür arasında yepyeni etkileşimlerin ortaya çıkmasına vesile olmaktadır. Kültür, coğrafi etkilere açık olmakta birlikte, kendisi de mekâna bir varlık kazandırma aracı durumundadır. Teknik ve teknolojik gelişimin bir etkisi olmasa da ve yaşanılan yer (fiziksel) bir mekân olarak aynı kalsa bile, kültür ona yeni bir varlık kazandırır; diğer bir ifadeyle kendine özgü bir kültürel zaman kurgular. Doğduğumuz yer, bizde acı veya tatlı anıları olan yerler, herhangi bir mekân değildirler: onlar hatıralarımızın varlık kazandırdığ 1 yerlerdir. Toplum da kendi tarihine bağlı olarak, coğrafyasına, -kültürel bir- varlık kazandırır; daha doğrusu kazandırabildiği ölçüde ve kazandırdığı şekliyle -şimdi üzerindengeleceği inşa edebilir, kurgulayabilir.

Tarihe şimdi üzerinden varlık kazandırılmazsa, o bir övünme vesilesi olmaktan ve şiirsel bir şekilde esip insanı tatlı hayallere dalmasına yol açmaktan başka bir işe yaramaz.

Günlük kullanımda zaman, iletişimin bir gereği olarak, geçip giden özelliğe sahip olacak şekilde düşünülür; fakat aslında, yukarıda da işaret edildiği gibi bu zaman tasavvuru bile farklı özellikleri içinde taşır. Özellikle günlük yaşantımızda geçmiş, artık var olmayan ve arkada kalmış bir özelliğe sahip olacak şekilde tasarlanır. Gelecek ise henüz mevcut olmayan, ne getireceği bilinemeyen bir özellik çerçevesinde düşünülür. Kültürel zaman açısından bakıldığında, gelecek,

${ }^{4} \mathrm{Bu}$ metinden haberdar olmamı sağlayan ve temin eden değerli meslektaşım Prof. Dr. Hüseyin Gazi Topdemir'e teşekkür ediyorum. 
şimdi aracılığıyla inşa edilebilecek, şimdi sayesinde akıl ile kavranabilen bir özelliğe sahiptir. F. Sezgin hocamız, yukarıda yaptığım alıntı da ifade ettiği gibi, geçmişi doğru kavramak ve yapılan hataları görmek gerekir; aksi taktirde geleceği inşa etmek mümkün olmayacaktır. Bu görüşün zıdd1, geçmişin aynen şimdi de tekrarının istenilmesidir. Dikkat edilirse böyle bir görüş, zamanın değişim ile ilişkisini koparacak, tek boyutlu kör bir akış içinde olduğunu, dolayısıyla geçmişin aynen tekrarını ve yaşatılmasını, hataların da aynen sürdürülmesini talep etmek durumunda olacaktır. Kültürel zaman, geleceğin akıl edilebilir ve kurgulanabilir olmasını; geçmişin şimdi üzerinden ve hep yeniden 'oku'manın gerekliliğini ifade etmektedir. Diğer bir ifadeyle "akıl edebilmek" geleceği idrak edebilmek, "oku”mak ise geçmişi şimdi üzerinden sürekli anlamaya çalışmak için gereklidir.

Geleceği inşa edebilmenin en temel koşulu, şehirdir; şehirler, geçmişin ve geleceğin kesişme noktasında bulunur ve şimdiyi biçimlerler. Yani şehirler bir toplumun tarihini ve hafızasını oluştururlar; daha da önemlisi, gerekli donanıma ve olanaklara sahip şehirler kültürel birikime olanak verirler ${ }^{5}$. Şehirler yeniden inşa edil(e)mezler; geçmişi geleceğe bağlayan bir köprü olarak düzenlenebilirler. Geçmişi şimdi üzerinden okuyamayan bir toplum, soyut bir geçmiş özlemi ile şimdiyi kurmaya çalışır; sonuç tarihi şehirlerin benliklerinin kaybolmasıdır. Halbuki şehirler, geleceği öngörmek suretiyle planlı bir şekilde düzenlenmesi gereken yerlerdir. Bu açıdan bakıldığında, bilim tarihine benzer bir rol üstlendiği söylenebilir. Şehir gibi bilim tarihi de bize geçmişin şifrelerini verir; fakat her ikisinin de geçmişe ilişkin özlem vesilesi olması, şimdinin kurulmasına hiç bir fayda sağlamayacaktır.

Müzeler, doğanın kendisi, hikayeler, masallar, efsaneler hep geçmişi aktarma aracıdırlar; onlardan gezerek, bakarak veya dinleyerek elbette bir şeyler öğrenmek mümkündür. Fakat dilini bilirsek doğa yeni şeyler söyleyebilir; müzeler, tarih bilgisi ve tarih bilinci varsa bugünün anlaşılmasına yardım edebilir; efsaneler, hikayeler, masallar bugün olup bitene ilişkin birşey söyleyecek şekilde yorumlanırsa tekrar yaşayabilir.

Doğa yasaları, hep varolandır; ve onun var-olması, ne şimdi üzerinden kurgulanır ne de şimdinin varlığını gerektirir. Newtoncu doğa yasalarının tanımladığı zaman, 'şimdi' hakkında bilgi vermediği gibi bu kavramın kullanılmasına da gerek duyulmaz. Fakat kültürel zaman, 'şimdi' dediğimiz bir zaman diliminin bağımsız varlığını şart koşar ve 'şimdi'ye kendine özgü bir varlık kazandırır. 'Şimdi'yi kültürel bir zaman dilimi olarak yorumlayabilmek için, öncelikle geçmişi ve geleceği herhangi (örneğin fiziksel) bir zaman dilimi olarak düşünmekten kurtulmak gereklidir. Fiziksel olaylar, mesela bir gezegenin geçmişteki konumu, 'şimdi'nin kendisine varlık kazandırma aracı değildir. Ne var ki kültürel açıdan bakıldığında geçmiş, 'şimdi'nin ve 'şimdi' de geleceğin varlık koşuludur. Buradaki temel sorun, şimdi'nin, geçmişle olan ilişkisini ve geleceğin inşasında oynadığı rolü anlayabilmektir. Geçmiş, şimdi ve geleceğin bu şekilde tanımlanabilmesinde temel koşul, kültürel bir beceriye ve birikime sahip olmak gerekir. Elbette kültürel beceri be birikim kendiliğinden oluşabilecek toplumsal bir haslet değildir; bunun mümkün olmasının (deyim yerindeyse) fiziki koşulu, şehirdir. Çünkü şehir, geçmişin şimdiye uzanmasına olanak verebilir; ama aynı zamanda şehir, sahip olduğu kültürel etkinliklere elverişli alt yapısı, iletişim ve ulaşım olanakları ile şimdi üzerinden geleceğin kurulmasını sağlayabilir. Evet, coğrafya bir kaderdir; ama şehir de kültürel zamanın coğrafyaya varlık kazandırması sayesinde o toplumun kaderini belirler. Kültürel zaman, 'şimdi' üzerinden, topluma kültürel bir seçicilik kazandırabilir. Kültürel seçiciliğin kalitesi, günlük magazinin, bireylerin yaşam biçimini ve tercihlerini yönlendirebilmesindeki (daha doğrusu yönlendirememesindeki) gücü ile ölçülebilir. Kültürel seçiciliğin olduğu yerde, başta da işaret edildiği gibi, toplumun bilim tarihine, felsefeye veya kısaca sosyal bilimlere, sanat etkinliklerine değer vermesi söz konusudur. Toplumsal seçicilik elbette toplumsal bir olgudur; fakat bu olgunun bir değer taşıyabilmesi, benimsenebilmesi ve geliştirilebilmesi için toplumsal kurumların (devletin, sivil toplum

${ }^{5}$ Şehirlerin bu özellikleri ile ilgili olarak bkz www.safakural.com adresindeki çeşitli yazılar 
örgütlerinin, eğitim kurumlarının vs.) bilinçli hareket etmesine ihtiyaç vardır. Düşünce tarihi, bu ilişkiler ağının çıkış noktasında filozofların olduğunu söylemektedir.

\section{Kaynakça}

Sezgin, F. (2008). Islam'da Bilim ve Teknik (Cilt 1). (H. Kaplan, A. Aliy, Dü, \& A. Aliy, Çev.) İstanbul: Türkiye Bilimler Akademisi, İstanbul Büyükşehir Belediyesi, T.C. Kültür ve Turizm Bakanlı̆̆ı.

Demir, R. ve Gökdoğan, M. D. (2008). Aydın Sayıll, Atatürk Kültür Merkezi Yay. 354. 